\title{
EVALUASI DIRI SEKOLAH (EDS) PADA SEKOLAH MENENGAH PERTAMA NEGERI DI KECAMATAN BANTAN KABUPATEN BENGKALIS
}

\author{
Dian Ratna Suri (1) \\ Isjoni $^{(2)}$ \\ Zulfan Saam ${ }^{(3)}$ \\ 1)Post Graduate Student of Riau University \\ ${ }^{2)}$ Lecturer of Education Management Study Programme PPs University of Riau \\ ${ }^{3}$ Lecturer of Education Management Study Programme PPs University of Riau
}

\begin{abstract}
This research generally aims to provide an overview of the implementation of school self-evaluation (EDS) at junior high schools in the District Bantan Bengkalis district. Based on the observation that researchers do, there are problems associated with the implementation of the EDS program in some of the junior high school in sub Bantan: 1) Understanding teachers and parents will EDS program is still low due to lack of socialization; 2) Components of schools do not have the time to implement EDS EDS considered that the additional burden of school; and 3) Charging EDS instruments are not in accordance with the existing conditions. This research uses evaluation methods Goal Attaiment developed by Tyler in 1950 . The study was the evaluation study, the research describes the problems associated with the implementation of school self-evaluation (EDS) in Junior High School District Bantan. Components that are evaluated include: Implementation of the EDS program, Constraints and challenges in the implementation of EDS, and the impact of the implementation of the EDS program. Techniques and Procedures collection DataPada this research through the study of documents, observation and interviews. Data and Data Sources, Data used in this study is a schematic, narrative, description and explanation of data from informants either orally or data in the form of a written document. Factors driving the implementation of the EDS internally is (1) HR; (2) coordination between stakeholders; (3) communication and a sense of family among the school community, externally is the support of the Department of Education and Culture and the motivation of LPMP. Internally inhibiting factor is (1) saturation with EDS instruments; (2) short time; (3) lack of understanding of teachers, externally are (1) changes in the system and EDS instruments and (2) the number of inquiries on the instrument. Impact of EDS among others (a) facilitate the school in making RKS / RKAS and (b), enables schools to identify deficiencies, the excess will be the performance of the school, the strength of the school to be developed as well as the challenges faced by the school. EDS benefits include (a) a school can have a data base for the development and improvement of quality in the future, (b) the results of EDS used the school to encourage schools to improve and enhance the quality and performance of the school. Follow-up of the school is based on the results of EDS is the repair, improvement and development of appropriate school performance 8 SNP.
\end{abstract}

Key words: school self-evaluation (eds), junior high schools

ABSTRAK: Penelitian ini secara umum bertujuan untuk memberikan gambaran tentang pelaksanaan evaluasi diri sekolah (EDS) pada sekolah menengah pertama negeri di kecamatan bantan kabupaten bengkalis. Berdasarkan hasil observasi yang peneliti lakukan, ditemukan beberapa permasalahan terkait dengan pelaksanaan program EDS di beberapa SMP yang ada di kecamatan Bantan: 1) Pemahaman guru dan orang tua siswa akan program EDS masih 
rendah karena kurangnya sosialisasi; 2) Komponen sekolah tidak memiliki waktu untuk melaksanakan EDS sehingga EDS dianggap beban tambahan sekolah; dan 3) Pengisian instrumen EDS tidak sesuai dengan kondisi yang ada. Penelitian ini menggunakan metode evaluasi Goal Attaiment yang dikembangkan oleh Tyler pada tahun 1950. Penelitian bersifat studi evaluasi, penelitian mendeskripsikan masalah yang berkaitan dengan pelaksanaan evaluasi diri sekolah (EDS) di SMP Negeri Kecamatan Bantan. Komponen yang dievaluasi meliputi: Implementasi program EDS, Kendala dan tantangan dalam penerapan EDS, dan Dampak penerapan program EDS. Teknik dan Prosedur Pengumpulan DataPada penilitian ini melalui studi dokumen, observasi dan wawancara. Data dan Sumber Data, Jenis data yang digunakan dalam penelitian ini bersifat skematik, narasi, uraian dan penjelasan data dari informan baik secara lisan maupun data dalam bentuk dokumen yang tertulis. Faktor pendorong pelaksanaan EDS secara internal adalah (1) SDM; (2) koordinasi antar stakeholder; (3) komunikasi dan rasa kekeluargaan antar warga sekolah, secara eksternal adalah dukungan dari Dinas Pendidikan dan Kebudayaan dan motivasi dari LPMP. Faktor penghambat secara internal adalah (1) kejenuhan terhadap instrumen EDS; (2) singkatnya waktu; (3) kurangnya pemahaman guru, secara ekternal adalah (1) perubahan sistem dan instrumen EDS dan (2) banyaknya pertanyaan pada instrumen. Dampak EDS antara lain (a) mempermudah sekolah dalam pembuatan RKS/RKAS dan (b) mempermudah sekolah untuk mengidentifikasi kekurangan, kelebihan akan kinerja sekolah, kekuatan yang dimiliki sekolah untuk dikembangkan serta tantangan yang akan dihadapi sekolah. manfaat EDS antara lain (a) sekolah dapat memiliki data dasar guna pengembangan dan peningkatan mutu di masa yang akan datang, (b) hasil EDS dipergunakan sekolah untuk mendorong sekolah memperbaiki dan meningkatkan mutu serta kinerja sekolah. Tindak lanjut sekolah berdasarkan hasil EDS adalah perbaikan, peningkatan dan pengembangan kinerja sekolah sesuai 8 SNP.

Kata Kunci:evaluasi diri sekolah (eds), sekolah menengah pertama negeri

\section{PENDAHULUAN}

EDS merupakan evaluasi internal yang yang dilaksanakan oleh semua pihak atau pendiri pendidikan (stakeholders) di sekolah untuk mengetahui secara menyeluruh kinerja sekolah dilihat dari pencapaian SPM dan 8 SNP dan mengetahui kekuatan serta kelemahannya secara signifikan sehingga akan diperoleh masukan untuk membuat Rencana Pengembangan Sekolah (RPS) dan Rencana Kegiatan Sekolah (RKS) dalam upaya peningkatan mutu pendidikan yang berkelanjutan.

EDS juga merupakan instrument utama dalam implementasi tahapan SPMP. Secara singkat, tahapan SPMP dimulai dari (1) pengumpulan data, (2) analisis data, (3) pelaporan/pemetaan, (4) penyusunan rekomendasi, dan (5) upaya pelaksanaan rekomendasi dalam bentuk program peningkatan mutu pendidikan. Dalam implementasi Tahap 1 SPMP, EDS menjadi alat untuk pengumpulan data tentang capaian 8 (delapan) Standar Nasional Pendidikan (SNP) oleh sekolah. Jadi, secara garis besar, EDS terdiri dari 8 (delapan) bagian sesuai dengan masing-masing SNP.

Sekolah yang merupakan pelaksana pendidikan secara formal berpeluang untuk mengatur proses pendidikan sesuai dengan potens ilingkungan yang ada baik dari perencanaan, pelaksanaan, monitoring serta pengambilan keputusan kebijakan. Tetapi segala macam pengelolaan pendidikan yang dibuat tetap harus mengacu pada kebijakan pusat yaitu sesuai dengan Standar Nasional Pendidikan (SNP) mulai dari standar kelulusan, isi, proses, sarana prasarana, pendidik dan tenaga pendidik, pengelolaan, pembiayaan, hingga standar penilaian. Ini sesuai dengan Peraturan Pemerintah (PP) Nomor 19 Tahun 2005 tentang Standar Nasional Pendidikan (SNP), Standar nasional pendidikan adalah kriteria minimal tentang system 
pendidikan di seluruh wilayah hukum Negara Kesatuan Republik Indonesia berfungsi sebagai dasar bagi perencanaan, pelaksanaan, dan pengawasan pendidikan pada setiap satuan pendidikan dalam rangka mewujudkan pendidikan nasional yang bermutu.

Berdasarkan hasil observasi awal yang peneliti lakukan, ditemukan beberapa permasalahan terkait dengan pelaksanaan program EDS di beberapa SMP yang ada di kecamatan Bantan: 1) Pemahaman guru dan orang tua siswa akan program EDS masih rendah karena kurangnya sosialisasi; 2) Komponen sekolah tidak memiliki waktu untuk melaksanakan EDS sehingga EDS dianggap beban tambahan sekolah; dan 3) Pengisian instrumen EDS tidak sesuai dengan kondisi yang ada.

Oleh sebab itu berdasarkan kondisi yang diuraikan di atas, peneliti tertarik untuk melakukan penelitian yang terkait dengan pelaksanaan program Evaluasi Diri Sekolah (EDS) di SMP Negeri Kecamatan Bantan sebagai bentuk dari hubungan timbal balik antara sekolah dengan pemerintah daerah yang merupakan bagian dari budaya pengembangan dan penjaminan mutu pendidikan.

\section{METODE PENELITIAN}

Penelitian ini menggunakan metode evaluasi Goal Attaiment yang dikembangkan oleh Tyler pada tahun 1950. Penelitian bersifat studi evaluasi, penelitian mendeskripsikan masalah yang berkaitan dengan pelaksanaan evaluasi diri sekolah (EDS) di SMP Negeri Kecamatan Bantan. Komponen yang dievaluasi meliputi: Implementasi program EDS, Kendala dan tantangan dalam penerapan EDS, dan Dampak penerapan program EDS. Tujuan dari penelitian ini adalah untuk menggambarkan implementasi program Evaluasi Diri Sekolah (EDS), menggambarkan kendala dan tantangan dalam penerapan program, serta untuk menggambarkan dampak penerapan program EDS bagi pengembangan SMP Negeri Kecamatan Bantan kabupaten bengkalis.
Objek dalam penelitian ini adalah Pelaksanaan program EDS di SMP Negeri Kecamatan Bantan yang melibatkan komponen sekolah seperti kepala sekolah, guru, komite sekolah, orang tua, masyarakat dan juga pengawas sekolah. Setiap komponen memiliki peran dan fungsinya masing-masing. Peran orang tua dan masyarakat menjadi satu dan tergabung kedalam komite sekolah. Teknik pengumpulan data dalam penelitian ini melalui studi dokumentasi, observasi dan wawancara. Ketiga teknik ini digunakan dengan harapan dapat memperoleh data dan informasi yang diperlukan dan dapat saling menunjang dan saling melengkapi. Analisis data merupakan suatu proses mengatur urutan data dan mengorganisasikannya dengan menafsirkan yaitu member arti signifikan terhadap data yang telah didapat, menjelaskan pola uraian dan mencari hubungan antar auraian tersebut. Analisis pada dasarnya adalah mengatur, mengurutkan, mengelompokkan, dan mengkatagorikan data yang diperoleh. Setelah itu ditarik kesimpulan yang berkaitan dengan permasalahan penelitian. Jika hasil analisis data sudah dapat menjawab pertanyaan penelitian, berarti tujuan penelitian sudah dapat tercapai.

\section{HASIL DAN PEMBAHASAN}

\section{Subfokus 1 Implementasi program EDS di SMP Negeri Kecamatan Bantan.}

Penelitian ini memiliki tujuan untuk Untuk menggambarkan implementasi program Evaluasi Diri Sekolah (EDS) di SMPNegeri Kecamatan Bantan, Untuk menggambarkan kendala dan tantangan dalam penerapan program EDS di SMP Negeri Kecamatan Bantan. Dan untuk menggambarkan dampak penerapan program EDS bagi pengembangan SMP Negeri Kecamatan Bantan. maka data hasil penelitian ini kemudian difokuskan kedalam tiga (3) komponen inti, yaitu: 1)Implementasi program EDS di SMP Negeri Kecamatan Bantan.2) Kendala dan tantangan dalam penerapan program EDS di SMP Negeri Kecamatan Bantan.3) Dampak penerapan program EDS 
bagi pengembangan di SMP Negeri Kecamatan

Bantan. Teknik pengumpulan data penelitian dilakukan dengan dokumentasi, observasi dan wawancara.

\section{Subfokus 2 Kendaladantantangandalampenerapan program EDS di SMP Negeri Kecamatan Bantan}

\begin{tabular}{|c|c|c|}
\hline SMP Negeri 1 Bantan & SMP Negeri 5 Bantan & SMP Negeri 6 Bantan \\
\hline $\begin{array}{l}\text { 1. Tantangan dan kendala } \\
\text { dalam penerapan EDS di } \\
\text { SMP Negeri 1 Bantan } \\
\text { meliputi faktor pendukung } \\
\text { dan factor penghambat } \\
\text { yang mempengaruhi } \\
\text { berjalannya proses EDS } \\
\text { tersebut, } \\
\text { 2. Faktor pendukung } \\
\text { terjadinya pelaksanaan } \\
\text { EDS di SMP Negeri 1 } \\
\text { Bantan menurut kepala } \\
\text { sekolah (HM) adanya } \\
\text { kerja sama tim yang baik } \\
\text { dan pengetahuan guru- } \\
\text { guru akan teknologi } \\
\text { karena pengisian } \\
\text { instrumen EDS } \\
\text { menggunakan aplikasi } \\
\text { komputer. } \\
\text { Faktor penghambatnya } \\
\text { antara lain: Banyaknya } \\
\text { pertanyaan pada } \\
\text { instrumen, kejenuhan } \\
\text { yang dialami para } \\
\text { responden dalam } \\
\text { pengisian instrumen, serta } \\
\text { waktu untuk mengisi } \\
\text { instrument sangat singkat. }\end{array}$ & $\begin{array}{ll}\text { 1. } & \text { faktor pendukung } \\
\text { terjadinya pelaksanaan } \\
\text { EDS di SMP Negeri } 5 \\
\text { Bantanmenurut kepala } \\
\text { sekolah (SP) harus adanya } \\
\text { kerja sama tim yang baik } \\
\text { dan pengetahuan guru- } \\
\text { guru. } \\
\text { 2. } \\
\text { faktor penghambatnya } \\
\text { antara lain: kurangnya } \\
\text { sosialisasi yang dilakukan } \\
\text { oleh LPMP sehingga dan } \\
\text { kurangnya kepedulian } \\
\text { pengawas SMP Negeri } 5 \\
\text { Bantan akan pentingnya } \\
\text { EDS. }\end{array}$ & $\begin{array}{l}\text { 1. Tantangannya adalah } \\
\text { membutuhkan kerja } \\
\text { sama antara seluruh } \\
\text { stekholder. Sulitnya } \\
\text { membangun kerjasama } \\
\text { dengan seluruh } \\
\text { stekholder dalam } \\
\text { melaksanakan EDS. } \\
\text { Dan program EDS } \\
\text { yang belum } \\
\text { menyeluruh kepada } \\
\text { seluruh komponen } \\
\text { sekolah. } \\
\text { faktor pendukung } \\
\text { didalam pelaksanaan } \\
\text { program EDS yaitu } \\
\text { guru mudah diajak } \\
\text { bekerja sama dalam } \\
\text { mengisi instrumen } \\
\text { EDS, Kepala sekolah } \\
\text { sudah mengikuti } \\
\text { sosialisasi program } \\
\text { EDS oleh LPMP dan } \\
\text { pengawas siap } \\
\text { memberikan bimbingan } \\
\text { terhadap program EDS } \\
\text { yang dilaksanakan di } \\
\text { SMP Negeri 6 Bantan. } \\
\text { faktor penghambat, } \\
\text { menurut hasil } \\
\text { penelitian yang } \\
\text { dilakukan oleh } \\
\text { Hendarman tentang } \\
\text { "Kendala-kendala } \\
\text { pelaksanaan Evaluasi } \\
\text { Diri Sekolah (EDS)" } \\
\text { yang hasilnya } \\
\text { menunjukkan bahwa } \\
\text { kendala-kendala yang } \\
\text { dihadapi meliputi aspek } \\
\text { konsep, instrumen, } \\
\text { insfrastruktur, sumber } \\
\text { daya manusia, dan } \\
\text { administrasi. }\end{array}$ \\
\hline
\end{tabular}


Dari ketiga sekolah yang peneliti lakukan dapat dilihat hasil Evaluasi Diri Sekolah (EDS) yang dilaksanakan, bahwasanya ketiga sekolah tersebut telah melaksanakan EDS disetiap tahunnya. SMP Negeri 1 telah melaksanakan EDS yang dengan baik terbukti hasilnya mendapat hasil EDS berdasarkan 8 indikator yaitu 3,49. Hal ini karena pelaksanaan koordinasi EDS diSMP Negeri 1 Bantan baik, kerja sama tim dan keterlibatan kepala sekolah dan pengawas. Hasil EDS yang dilaksanakan oleh SMP Negeri 5 Bantan termasuk Cukup karena pada SMP 5 Bantan kurang mendapatkan sosialisasi dari LPMP, kurangnya tanggung jawab dari masing-masing komponen sekolah dan koordinasi pelaksanaan yang kurang baik. Pelaksanaan EDS yang dilakukan oleh SMP Negeri 6 Bantan dikategorikan Cukup karena pelaksanaan EDS di SMP Negeri 6Bantan hanya dikerjakan oleh beberapa komponen.

Instrumen EDS merupakan alat utama yang akan dipakai dalam EDS untuk memperoleh serangkaian informasi tentang seluruh kinerja sekolah mengacu pada ketentuan SPM dan SNP. Dengan demikian maka instrumen EDS dituliskan berdasarkan kedelapan standar dalam SNP yang berisi tentang standar isi, proses, kompetensi lulusan, pendidik dan tenaga kependidikanm sarana dan prasarana, pengelolaan, pembiayaan dan penilaian.Berdasarkan temuan penelitian, penulis berpendapat untuk langkah kedepan pelaksanaan EDS adalah 1) Pelaksanaan EDS lebih dimatangkan lagi sehingga permasalahan yang akan muncul bisa diminimalisir 2) Proses sosialisasi EDS harus dilaksanakan setiap tahun. Pada tahap sosialisasi lebih diintensifkan agar seluruh komponen sekolah lebih memahami tentang bagaimana proses EDS itu berjalan dan tidak terjadi kesalahan didalam setiap pengisian instrumen 3) memperbaiki kesalahan- kesalahan yang terjadi selama proses EDS berlangsung 4) me-review kembali pelaksanaan program EDS untuk mengidentifikasi kekurangan serta kesalahan agar tidak terulang kembali.
Berdasarkan temuan penelitian, dapat dijabarkan beberapa dampak penerapan program EDS antara lain (a) mempermudah sekolah dalam pembuatan RKS/RKAS dan (b) mempermudah sekolah untuk mengidentifikasi kekurangan, kelebihan akan kinerja sekolah, kekuatan yang dimiliki sekolah untuk dikembangkan serta tantangan yang akan dihadapi sekolah. Manfaat yang dapat diambil antara lain (a) sekolah dapat memiliki data dasar guna pengembangan dan peningkatan mutu di masa yang akan datang, (b) hasil EDS dipergunakan sekolah untuk mendorong sekolah memperbaiki dan meningkatkan mutu serta kinerja sekolah dan (c) dapat mengidentifikasi jenis dukungan yang dibutuhkan oleh sekolah. Dan tindak lanjut hasil EDS untuk pengembangan sekolah di masa datang antara lain sebagai berikut: (a) berdasarkan Standar isi, pengembangan kurikulum yang melibatkan guru, komite sekolah, kepala sekolah, konselor, dan pihak-pihak yang terkait. (b) Standar proses, pengembangan RPP, silabusdan proses pembelajaran yang bermutu. (c) Standar kompetensi lulusan, peningkatan siswa memperoleh pengalaman belajar agar mendapatkan pengetahuan untuk melanjutkan kejenjang pendidikan yang lebih tinggi. (d) Standar PTK (Pendidik dan Tenaga Kependidikan), meningkatkan jumlah guru yang memiliki sertifikat kompetensi dan mempertahankan jumlah guru yang mempunyai kualifikasi minimal. (e) Standar sarpras, peningkatan bangunan sesuai ketentuan SNP dan peningkatan kelengkapan laboratorium, ruang guru dan ruang kelas. (f) Standar pengelolaan, mempertahankan sekolah memiliki dokumen RKS/RKAS (Rencana Kegiatan Sekolah / Rencana Kegiatan Anggaran Sekolah) dan mempertahankan sosialisasi visi, misi dan tujuan sekolah kepada semua warga sekolah. (g) Standar pembiayaan, peningkatan partisipasi masyarakat dalam rapat penetapan besaran pembiayaan yang ditanggung orang tua murid dan (h) Standar penilaian, mempertahankan hasil penilaian digunakan untuk memperbaiki proses belajar mengajar. 


\section{SIMPULAN DAN SARAN}

Simpulan dalam penelitian ini yaitu;

1. Implementasi EDS dilakukan oleh SMP Negeri 1 Bantan, SMP Negeri 5 Bantan dan SMP Negeri 6 Bantan.

2. Faktor pendorong pelaksanaan EDS secara internal adalah (1) SDM; (2) koordinasi antar stakeholder; (3) komunikasi dan rasa kekeluargaan antar warga sekolah, secara eksternal adalah dukungan dari Dinas Pendidikan dan Kebudayaan dan motivasi dari LPMP. Faktor penghambat secara internal adalah (1) kejenuhan terhadap instrumen EDS; (2) singkatnya waktu; (3) kurangnya pemahaman guru, secara ekternal adalah (1) perubahan sistem dan instrumen EDS dan (2) banyaknya pertanyaan pada instrumen.

3. Dampak EDS antara lain (a) mempermudah sekolah dalam pembuatan RKS/RKAS dan (b) mempermudah sekolah untuk mengidentifikasi kekurangan, kelebihan akan kinerja sekolah, kekuatan yang dimiliki sekolah untuk dikembangkan serta tantangan yang akan dihadapi sekolah. manfaat EDS antara lain (a) sekolah dapat memiliki data dasar guna pengembangan dan peningkatan mutu di masa yang akan datang, (b) hasil EDS dipergunakan sekolah untuk mendorong sekolah memperbaiki dan meningkatkan mutu serta kinerja sekolah. Tindak lanjut sekolah berdasarkan hasil EDS adalah perbaikan, peningkatan dan pengembangan kinerja sekolah sesuai 8 SNP.

Berdasarkan dari simpulan di atas maka rekomdasi pada penelitian pelaksanaan Evaluasi diri Sekolah (EDS) di SMP Negeri Kecamatan Bantan Kabupaten Bengkalis adalah sebagai berikut:

\section{Kepala Sekolah}

Kepala sekolah diharapkan lebih memotivasi para komponen sekolah untuk mensukseskan pelaksanaan program EDS dan selain mengawasi serta mengatur, kepala sekolah diharap ikut terjun langsung mengawasi proses EDS tersebut.

2. TPS atau Tim EDS

Tim EDS diharapkan lebih mengkoordinasi seluruh komponen sekolah yang terlibat dalam proses EDS dan lebih mengintensifkan sosialisasi EDS kepada seluruh warga sekolah agar dapat meminimalisir kesalahan yang terjadi saat pelaksanaan EDS. Serta diharapkan mengevaluasi kerja tim setelah program terlaksana.

3. Pengawas Sekolah

Pengawas sekolah diharapkan lebih sering datang ke sekolah untuk mengawasi proses berjalannya program EDS dan diharapkan lebih membangun interaksi dan komunikasi yang baik dengan para pemangku sekolah agar proses EDS berjalan dengan lancar.

4. Dinas Pendidikan dan Kebudayaan Dinas Pendidikan dan Kebudayaan diharapkan lebih intensif dalam memberikan sosialisasi kepada sekolah, bersifat terbuka dan membantu saat sekolah mengalami kesulitan dalam proses EDS serta lebih meningkatkan komunikasi dengan sekolah agar tidak terjadi miss-communication.

5. LPMP

Untuk LPMP diharapkan lebih komunikatif dan lebih memotivasi para pengawas dan kepala sekolah saat memberikan sosialisasi pengisian instrumen EDS dan selalu mengevaluasi kembali setelah selesai melakukan sosialisasi agar meminimalisir kesalahan.

6. Peneliti Lain

Untuk peneliti lain diharapkan penelitian ini menjadi bahan referensi dan informasi dalam melakukan penelitian dibidang yang sama yaitu Evaluasi Program Pendidikan dan Analisis Kebijakan. Dan semoga penelitian ini dijadikan bahan pustaka dalam mengerjakan laporan dan peneliti berharap agar mengembangkan penelitian yang relevan dengan penelitian ini. 


\section{DAFTAR PUSTAKA}

A.G Subarsono.2008. Analisis Kebijakan Publik. Yogyakarta :PustakaPelajar.

BahtiarIrianto, Yoyon. Kebijakan Pembaruan Pendidikan ,Konsep, Teori, dan Model. Jakarta : PT. Raja Grafindo Press, 2011.

Header Akib dan Antonius Tarigan, Artikulasi Konsep Implementasi Kebijakan: Perspektif, Model dan Kriteria Pengukurannya. Jurnal, 2000.

Iskandar, Metodologi Penelitian Pendidikan dan Sosial, Referensi, Jakarta. 2013.
Kementerian. 2010. Panduan Teknis Evaluasi Diri Sekolah dan Madrasah (EDS/M). Jakarta.

Maryono, Menakar Kebijakan RSBI: Analisis Kritis Studi Implementasi, Yograkarta. Sukmadinata, Nana Syaodih, et al., 2006, Pengendalian Mutu Pendidikan Sekolah Menengah (Konsep, Prinsip dan Instrumen), Refika Aditama, Bandung. Sugiyono, Metode Penelitian Pendidikan, Alfabeta. Bandung. 2011. 